\title{
Intrapulmonary psammomatous melanotic schwannoma
}

\author{
Yee-Fung Lin, MD, ${ }^{\mathrm{a}}$ Sheng-Chuan Hsi, MD, ${ }^{\mathrm{a}}$ Junn-Liang Chang, PhD, ${ }^{\mathrm{b}}$ and Chun-Hsiung Huang, MD, ${ }^{\mathrm{a}}$ Taiwan, Republic of China
}

Intrapulmonary psammomatous melanotic schwannoma is rare: Only 1 case has been reported in the English literature. ${ }^{1}$ Intrathoracic schwannoma is more common in adults $^{2,3}$ and should be differentiated from melanotic schwannoma in young patients. We present a case of primary psammomatous melanotic schwannoma originating in the pulmonary parenchyma and discuss the possible clinical and pathologic associations in the present literature.

\section{CLINICAL SUMMARY}

A 15-year-old girl who was a nonsmoker was admitted because of the incidental finding of a lung mass on a chest $\mathrm{x}$-ray for scoliosis (Figure 1, $A$ ). On admission (Ward of Thoracic Surgery Division of Thoracic Surgery, Department of Surgery), she was asymptomatic and there were no skin pigmentation abnormalities. A series of laboratory examinations, including tumor marker, showed normal results. A chest roentgenogram and contrast-enhanced computed tomography scan showed a well-circumscribed mass approximately $7.0 \times 6.0 \mathrm{~cm}$ with fat and calcified density in the right upper lobe adjacent to the bronchus (Figure 1, B). Because the tumor was larger than $3.0 \mathrm{~cm}$ in diameter and had an intrapulmonary location, it had to be distinguished from lung cancer.

On day 3 after the patient's admission, we performed a right posterolateral thoracotomy via the fourth intercostal space with the patient under general anesthesia. Initially, we attempted to enucleate the tumor. The tumor adhered to the bronchus; it was difficult to detach them from each other so enucleation was converted to a lobectomy. The procedures were changed to prevent the recurrence of a residual tumor from an incomplete initial resection. We dissected the superior pulmonary vein and the superior trunk of the pulmonary artery followed by ligation. The bronchus of the right upper lobe was exposed adequately and managed with a TA 30-3.5 device (Manufactured by United States Surgical, a division of Tyco Healthcare Group LP, Norwalk, Conn. USA). The right upper lobectomy was per-

\footnotetext{
From the Division of Thoracic Surgery, Department of Surgery ${ }^{\mathrm{a}}$ and Department of Pathology and Laboratory Medication, ${ }^{\mathrm{b}}$ Armed Forces Tao-Yuan General Hospital, Taiwan, Republic of China.

Received for publication April 15, 2008; accepted for publication June 10, 2008. Address for reprints: Chun-Hsiung Huang, MD, Division of Thoracic Surgery, Department of Surgery, Armed Forces Tao-Yuan General Hospital, No. 168, Jhongsing Road, Longtan Township, Taoyuan County 325, Taiwan, Republic of China (E-mail: qbraintw@yahoo.com.tw).

J Thorac Cardiovasc Surg 2009;137:e25-7

$0022-5223 / \$ 36.00$

Copyright (c) 2009 by The American Association for Thoracic Surgery

doi:10.1016/j.jtcvs.2008.06.023
}

formed successfully. The patient was ventilated for 9 hours and recovered uneventfully. She was asymptomatic 5 months after the operation.

The submitted lung mass specimen measured $8.0 \times 6.0 \times$ $4.0 \mathrm{~cm}$, weighed $50.0 \mathrm{~g}$, and was attached to the sub-bronchial tress with gray brown in color. The tumor sections showed a well-defined encapsulated mass consisting of Antoni $\mathrm{A}$ and $\mathrm{B}$ areas (Figure 2, $A$ ) with marked myxoid degeneration. Immunohistochemical study presented positive staining for vimentin, S-100 protein, and Masson trichrome, but was negative for glial fibrillary acidic protein, actin, endothelial monocyte antigen, and creatine kinase. There was a marked homogeneous hypercellularity, interspersed melanin pigmentation, and deposition, which was positive for HMB-45 (Melanoma-associated antigen) stain (Figure 2, $B)$. There were numerous psammomatous calcified bodies (Figure 2, C) but no mitotic figures or atypical cells. All of these pathologic findings yielded a definitive diagnosis of psammomatous melanotic schwannoma.

\section{DISCUSSION}

Psammomatous melanotic schwannoma, a neural sheathderived tumor, may occur in the central and peripheral nervous systems, although it is most frequently found in the alimentary tract (favoring the stomach) and paraspinal sympathetic chain. It has a series of unusual characteristics that differentiate it from the classic schwannoma: the presence of melanin and psammoma bodies. Melanin-containing schwannoma does not necessarily demonstrate psammoma bodies. Approximately $10 \%$ of melanotic schwannomas are malignant, and those with no psammoma bodies may have a malignant change. ${ }^{4,5}$

The differential diagnosis of intrapulmonary melanotic schwannoma includes classic schwannoma and other pigmented lesions. In von Recklinghausen's disease, neurofibromatosis and schwannoma can occur in all areas of the nervous system. Approximately $14 \%$ of thoracic neurogenic tumors are associated with Recklinghausen's neurofibromatosis, ${ }^{3}$ whereas approximately half of adult cases with malignant tumor are reported. To our knowledge, no patient with psammomatous melanotic schwannoma has had proven von Recklinghausen's neurofibromatosis.

Melanotic schwannomas are readily distinguished from classic schwannomas because the former lack a distinct capsule and clear-cut Antoni A and B areas. Classic schwannoma rarely involves the gastrointestinal tract and lacks melanin, psammoma bodies, and fat. The major clinical difference between the schwannomas is that in more than half 

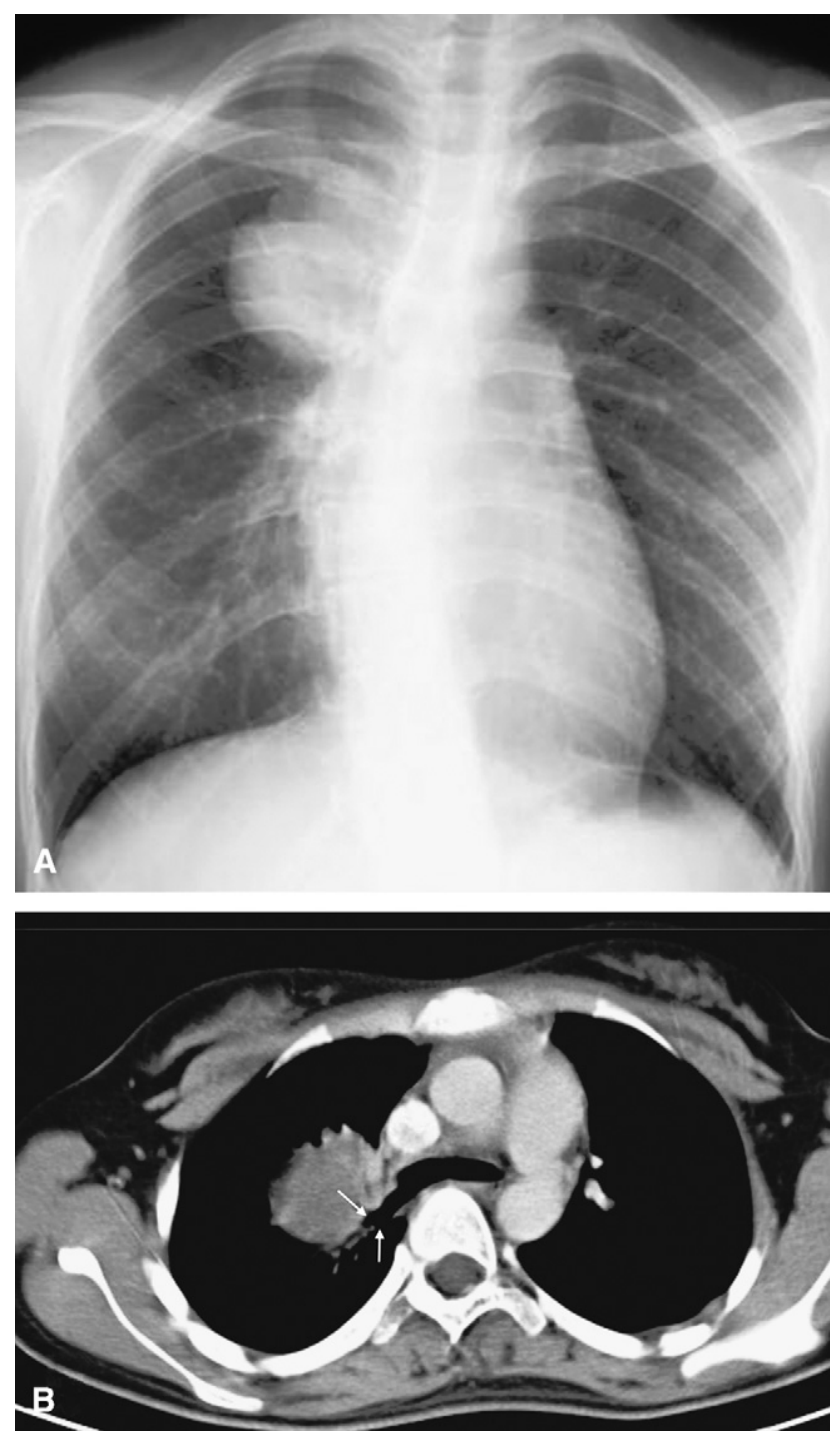

FIGURE 1. A, Chest $\mathrm{x}$-ray showing scoliosis and a round mass at the right upper lobe. B, Computed tomography scan showing a lobulated mass with soft tissue, fat, and calcified density attached to the bronchus (white arrows).

the cases, psammomatous melanotic schwannoma is a familial condition associated with Carney's syndrome. Once the syndrome is present, the tumor tends to occur at an earlier age (average age, 22.5 years). ${ }^{5}$

\section{CONCLUSIONS}

Intrapulmonary neurogenic tumors are essentially amenable to primary surgical therapy, and complete surgical removal alone leads to definite diagnosis and provides therapy. The psammomatous melanotic schwannoma is usually characterized by indolence, and it is not known to have Carney's complex on initial evaluation. Once the pathologic diagnosis was made in the presented patient, we recommended further investigation of both the patient and first-degree relatives for Carney's complex. Complete surgi-
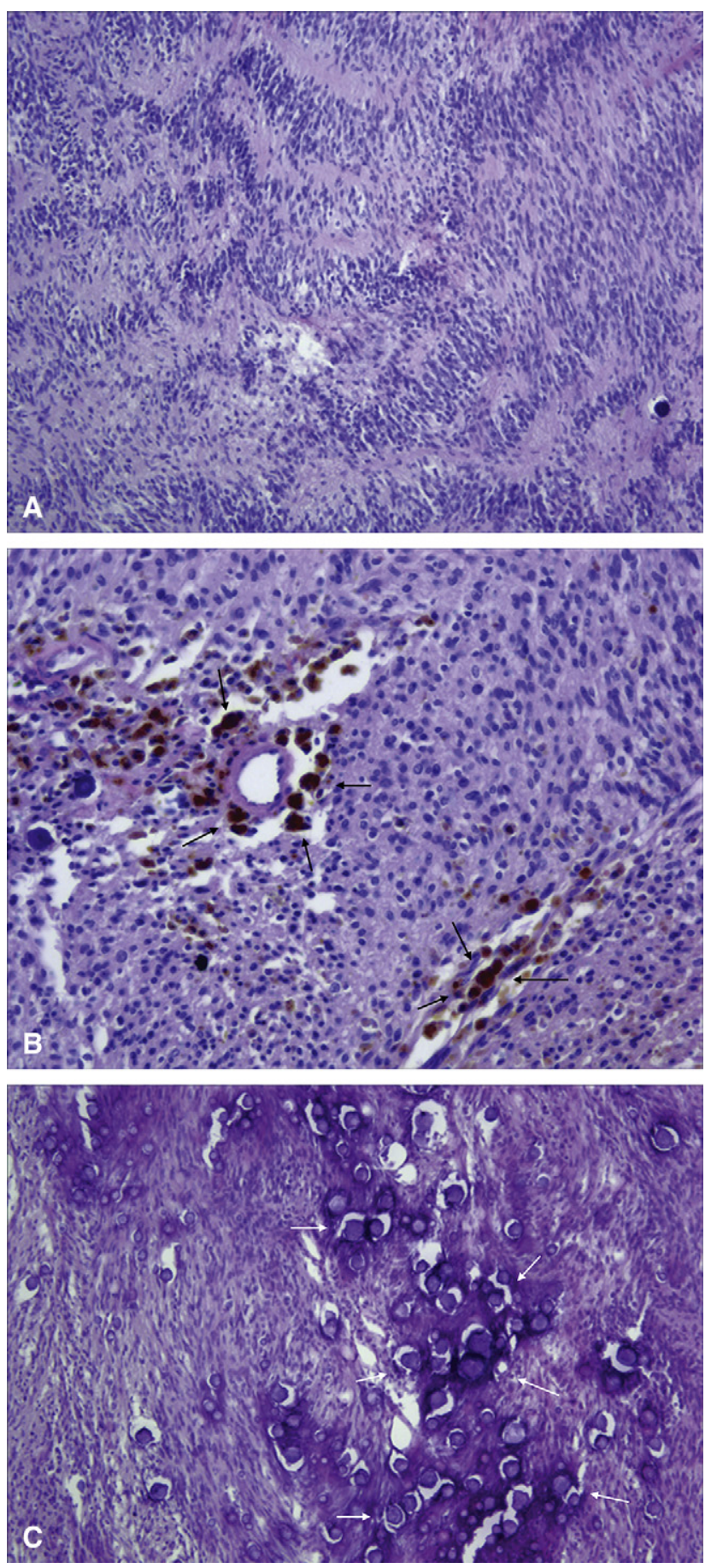

FIGURE 2. A, Tumor cells are arranged in whorled structures showing Antoni A and B areas (hematoxylin-eosin stain, original magnification $\times 100)$. The tumor contains intersperse melanin pigmentation (B, black arrows) and numerous psammomatous calcified bodies (C, white arrows) (HMB-45 stain, original magnification $\times 100$ ).

cal resection appears to be the optimal therapeutic option, hence there is a reasonably long follow-up of cases that initially were incompletely excised, and evidence of increased aggression. 


\section{References}

1. Simansky DA, Aviel-Ronen S, Reder I, Paley M, Refaely Y, Yellin A. Psammomatous melanotic schwannoma: presentation of a rare primary lung tumor. Ann Thorac Surg. 2000;70:671-2.

2. Takeda S, Miyoshi S, Minami M, Matsuda H. Intrathoracic neurogenic tumors-50 years' experience in a Japanese institution. Eur J Cardiothorac Surg. 2004;26: 807-12.

3. Ribet ME, Cardot GR. Neurogenic tumors of the thorax. Ann Thorac Surg. 1994; 58:1091-5.
4. Carney JA, Stratakis CA. Epithelioid blue nevus and psammomatous melanotic schwannoma: the unusual pigmented skin tumors of the Carney complex. Semin Diagn Pathol. 1998;15:216-24.

5. Carney JA. Psammomatous melanotic schwannoma. A distinctive, heritable tumor with special associations, including cardiac myxoma and the Cushing syndrome. Am J Surg Pathol. 1990;14:206-22.

\section{Low-grade sarcoma of the right upper lobe vein mimicking a metastatic disease}

Dominique Fabre, MD, Jeremie H. Lefevre, Vincent De Montpreville, Elie Fadel, Gaetano Rocco, Olivier Chataignier, Sacha Mussot, and Philippe G. Dartevelle, Paris, France

We present a case of a 23-year-old patient with a primary tumor of the right upper vein and endocavitary expansion in the left atrium associated with concomitant infiltrativelike lesions of the upper and middle lobes. These lesions were suspected to be metastatic. The richly vascularized tumor was completely removed on cardiopulmonary bypass through a right thoracotomy. The pathologic findings showed a low-grade sarcoma invading the left atrium. The clinically suspected pulmonary metastases were in reality venous infarcts of the right upper and middle lobes. A complete obstruction of the pulmonary veins may create intrapulmonary lesions that can mimic metastatic lesions and should not exclude surgical treatment.

\section{CLINICAL SUMMARY}

A 23-year-old man presented with recurrent hemoptysis after a pulmonary infection. The chest radiograph showed opacity of the right upper lobe. Chest computed tomography (CT) demonstrated a sizeable left atrial mass originating from the right upper vein (Figure 1, A) and 2 lesions in the right upper and middle lobes (Figure 1, B). Tumor markers were negative. Transesophageal echography showed a $5 \times 4-\mathrm{cm}$ tumor occluding the right upper

\footnotetext{
From the Department of Thoracic and Vascular Surgery and Heart Lung Transplantation, Marie-Lannelongue Hospital-Paris Sud University, Paris, France.

Received for publication March 16, 2008; revisions received April 15, 2008; accepted for publication May 5, 2008

Address for reprints: Dominique Fabre, MD, Department of Thoracic and Vascular Surgery and Heart Lung Transplantation, Marie-Lannelongue Hospital-Paris Sud University, 133 avenue de la résistance, 92350 Le Plessis Robinson, Paris, France (E-mail: d.fabre@ccml.fr)

J Thorac Cardiovasc Surg 2009;137:e27-9

0022-5223/\$36.00

Copyright (c) 2009 by The American Association for Thoracic Surgery

doi:10.1016/j.jtcvs.2008.05.050
}

vein without obstruction of the mitral valve. The tumor did not completely invade the wall of the left atrium. F18 fluorodeoxyglucose positron emission (PET) CT showed an intense fixation of the tumor with a moderate fixation of the pulmonary lesions (Figure 1, C). Maximum standardized uptake values were 4.39 for the left atrial tumor and 2.68 and 2.07 for pulmonary lesions. The CT angiography showed total occlusion of the right upper pulmonary vein (Figure 1, D). Preoperative heart catheterization showed a normal cardiac index and normal pulmonary pressure. Capillary pulmonary pressure showed a mean gradient of $6 \mathrm{~mm} \mathrm{Hg}$ between the left and the right pulmonary sides.

The operation was performed through a right posterolateral thoracotomy in the fifth interspace. After extrapleural dissection required by hypervascularized adhesions, a consolidated and retracted upper lobe, an enormous upper lobe vein, and the absence of extravascular tumor were observed. Normothermic cardiopulmonary bypass was established between both venae cavae and ascending aorta. Under aortic clamp and myocardial protection, the left atrium was opened around the venoatrial junction allowing en bloc removal of the upper bilobe and the intra-atrial tumor, which was floating free in the cavity. Reconstruction of the left atrium consisted of a simple plasty without narrowing the lower lobe vein. The bypass was stopped after deairing the left cavities, and the left atrium margins were tumor-free on frozen section (Figure 2, A).

The patient was extubated at the end of the procedure, had an uneventful postoperative course, and was discharged on day 14. Pathologic examination of the tumor identified a low-grade myxoid sarcoma (Figure 2, B). The mitotic index activity measured by $\mathrm{Ki}-67$ immunochemistry dosage was $10 \%$. 